\title{
QUEM FUNDOU PINDAMONHANGABA? (II).
}

\section{CESAR SALGADO}

$\Lambda$ polêmica está fora da moda. Longe vão os tempos em que dois ou mais contendores tomavam da pena e vinham para o palco da publicidade, quais esgrimistas, armados de florete, a trocar golpes que, de quando em quando, terminavam em duelos de verdade. E, se, por vezes, os altercantes se atinham cavalheirescamente às "regras do jogo", acontecia também, não raro, que, no "ardor da dicussão", se mimoseassem com epítetos infringentes do cóligo de boas maneiras.

Há ainda quem se lembra de certas polêmicas famosas, que eram o "prato do dia" dos meios literários do começo do século, como as que se travaram entre Rui Barbosa e Carneiro Ribeiro, Lafayette e Sílvio Romero, Júlio Ribeiro e o padre Sena Freitas, Eduardo Prado e Luís Pereira Barreto, Emílio de Meneses e Garcia Redondo, para citar apenas as de maior repercussão.

Hoje, não haveria ambiente para essas disputas, nem sempre justificáveis, em razão dos motivos que as ditavam.

Evidentemente, não é o caso desta permuta de opiniōes entre mim e o Professor Waldomiro de Abreu sobre a fundação de Pindamonliangaba. Nenhum de nós veio a público, movido por interesses pessoais, mas, tão só com o intuito de colaborar na elucidação daquele momentoso problema, hoje mais do que nunca oportuno, pois o tricentenário da cidade está aí.

Devo declarar, de início, ao ilustre professor Waldomiro de Abreu que eu bem desejaria encontrar-mé no perfil em que ele me retratou. Infelizmente, ou felizmente, aquela judiciosa advertência gnothi seauton, inscrita no pórtico do tempo de Delfos, lembra-me quão longe estou de merecer o alto juizo do meu nobre conterrâneo. Se, amanhã, quando o compasso do tempo me alertar de que está chegada a hora de voltar à terra de meu berço para o repouso da noite sem alvoradas, se a minha consciência me disser que eu não deslustrei o 
nome de filho de Pindamonganhaba, outro prêmio melhor eu não podcria ter ambicionado.

E, porque a polêmica está fora da moda e, porque, segundo penso, o leitor a esta altura deve ansiar pelo desfecho do certame, eu, reafirnando as minhas homenagens à inteligência, à cultura e à fidalguia do professor Waldomiro de Abreu, deixo expresso, desde já, que não voltarei ao debate.

\section{QUEM FUNDOU PINDAMONHANGABA?}

Eu aprendi, desde minha infância, que Pindamonhangaba havia sido fundada pelos irmãos Antônio Bicudo Leme e Brás Esteves Leme. Com o correr dos tempos, essa versão "por ouvir dizer" ganhou, a meu ver, foro de autenticidade, à vista de valiosos comprovantes históricos. E, assim como eu, gerações e gerações de pindamonhangabenses aprenderam a mesma lição.

Eis que um dia, o ilustre professor Waldomiro Leite de Abreu nos surprende:

"Meus caros conterrâneos, sinto muito, mas os fundadores de Pindamonhangaba não foram Antônio Bicudo Leme e Brás Esteves Leme"!

Ante esta imprevista revelação, todos nós nos sentimos desiludidos e algo vexados.

Foi como se tivessem dito a alguém que seu pai não era quem ele pensava. E, se o pobre, sucumbido ante essa triste revelação inquerisıe: "mas, então, quem é meu pai?" - e tivesse como resposta: "não sei" - é de se avaliar o sofrimento dessa criatura, degradada para o rol dos filhos de pai incógnito!

Pindamonhangaba, porém, não obstante o entendimento do professor Waldomiro de Abreu, tem paternidade clara e conhecida.

Vejamos em que se fundamenta esse enunciado.

Quem estudar a história das origens de Pindamonhangaba pode, inspirado em Carlos Drumond de Andrade, dizer: "encontrei um documento no meu caminho". Pois, esse documento, que para os tradicionalistas é uma prova irrefutável, para Waldomiro de Abreu passou a ser, "data vênia", "uma pedra no caminho"... 
Por mais que se afadigue o ilustre professor no afā de destruir ou remover essa pedra, digo, esse documento, ele permanece inarredível e inamolgável, como um marco, profundamente fincado no chäo da história.

Vamos examiná-lo, depurá-lo, criticá-lo e apreciá-lo, à luz dos processos científicos de avaliação da prova documental.

Antes de mais nada, urge conhecer na sua integra o referido documento, que ora se exibe, transcrito ipsis literes, da página 234 da segunda edição do livro Pindamonhangaba, de Ataíde Marcondes. Ei-1o:

"A Igreja desta freguezia hé da invocação de Nossa Senhora do Bom Sucesso: tem cinco altares, Altar mór, 2 colateraes e dous dos quaes para fóra que ambos são do Rosario dos brancos e dos pretos, Hé feita de teypas de pilam e naves de pau ripado, a coberta de telha. Hé forrada somente na Capella mór tem dous sinos sacrário dourados pia baptismal de pedra e hua na porta principal também de pedra. Hua lampada de prata e sacristia. Ha nesta matriz quatro irmandades de Compromissos que são: a do Santissimo Sacramento: - a da senhora do Bom Sucesso e das almas e a do Rosario dos pretos. Foi esta freguezia desmembrada da freguezia de São Francisco das Chagas de V.a de Taybaté sendo primeiro filial a capella da dita freguezia: foy fundada dita capella por Antonio Bicudo Leme ha trinta annos pouco mais au menos e sendo então este Logar sitio morada do dito fundador e pelos annos adiante. Com a acurencia de varios moradores que foram assituando veyo a ser a freguezia. E porque creceu o povo e a egreja era pequena Resolveram-se os moradores a fazer nova igreja que commodamente os pudesse agasalhar que é a que de presente está servindo ficando na matriz velha collocádo por ordem do Exmo. Rmo. senhor Bispo D. Antonio de Guadalupe uma veneranda imagem de S. José".

De onde vem esse documento? - Ataide, no trabalho citado esciarece: "por um documento que encontramos na matriz..." Faitou acrescentar - o que se afigura evidente - que esse documento constava do Livro do Tombo, o qual - dizemos nós - inexplicavelmente anda sumido.

Há motivos para duvidar da afirmativa de Ataide? 
Aqui, já se inicia o processo crítico de avaliação da peça em aprȩ̧o.

Indaguemos da probidade moral de Ataide e de seu conceito como historiador. - Ninguém ousará negar-lhe os predicados de um homem de bem. Os que com ele conviveram e os que, mais tarde, lhe estudarem a personalidade não discrepam em assinalar as virtudes de seu caráter, a sua honradez, a sua dignidade.

Como hi:toriador, se ele não foi, no rigor da palavra, um filósofo da história, um analista dos fatos históricos - e quão poucos no Brasil merecem esse título! - ele foi, entretanto, um investigador de méritos irrecusáveis, um pioneiro, que carreou preciosos subsídios para :) e tudo da história de Pindamonhangaba. Teve falhas, deslizes, contradições? Teve-os, certamente. Mas quem, na ciência, nas letras ou na história, pode eximir-se do reproche de haver claudicado, aqui on ali?

Quandoque bonus dormitat Homerus. Assim o escreveu Horácio em sua Arte Poética.

Se até os grandes, por vezes, cochilam?!...

Ciaston Boissier, membro do Instituto de França e Historiador dos mais apreciados, denuncia vários lapsos e até contradições nas obras históricas de Tácito (1). Entretanto, nem por isso, Tácito baixou nc conceito dos que o consideram, a exemplo de Frederico Lolié,

"Modelo de historiador, profundo e subtil a um só tempo, íntegro e dedicado, imparcial, mas sensivel, convicto, mas comedido e, por execelência, filósofo, moralista e pensador".

E, linhas adiante:

"Suas qualidades de historiador fizeram escola e permaneceram para a admiração dos séculos" (2).

Nem se diga que Tácito é um historiador superado, por força da evolução dos métodos histórico. Seu valor está exatamente na sua scbrevivência, como o atesta A. H. Mac Donald em Literary discussion and bibliography, referindo-se a ele:

(1). - Gaston Boissier, Tácito, pág. 97, trad. portuguêsa. Editora Difusora S. A., São Paulo.

(2). - Frederico Lolié, Dictionnaire des Ecrivains et des Littératures, pág. 288. Paris, 1914. 
"modernos estudiosos da história comprovaram seus assertos, examinaram suas opiniões, analizaram seus estilo de modo a permitir colczá-lo, com espírito crítico, entre os imortais" (3) .

Pois, se o grande Tácito apesar de suas derrapagens, mantem-se no pedestal em que o admiramos, por que negar crédito ao nosso Ataide, apontando este ou aquele senão na sua obra?

Neste passo, pesados os prós e os contras, podemos acompanhar João Martins de Almeida, no seu louvor:

"Acreditamos piamente em Ataide Marcondes. O seu Pindamonhangaba não teve outro intuito senão prestigiar a cidade; é obra imortal a despeito de tudo e de todos; nossos filhos e netos procurarão nesse livro a gênese de Pindamonhangaba; ele é a Bíblia da Princesa do Norte; apenas foi escrito por um só apóstolo" (4).

Assentes esses pressupostos sobre a idoneidade moral e a probidade de Ataide Marconde como historiador, estamos habilitados a acreditar que ele viu, leu e copiou o documento. Ademais se atentarmos nesse documento com olhos críticos somos forçados a concluir que Ataide não teria podido inventá-lo, a não ser que fosse um mistificador habilíssimo, capaz de forjar enredos históricos, perfeitamente verossimeis, e de ressuscitar arcaismos de todo e:quecido, como Hé, hua, teypas, pilan, foy, Taybaté.

Observe-se também o estilo, tipicsmente contemporâneo da época, atribuida ao documento, para se concluir que este, sob o aspecto formal é rigorosamente insuspeito. Examinemos agora o seu conteudo, a fim de aquilatar do seu quantum de credibilidade, dentro das circunstâncias de tempo e de lugar a que ele estava adstrito.

Que consta desse documento? - A descrição da igreja da freguesia de Nossa Senhora do Bom Sucesso de Pindamonhangaba e referência a uma capela fundada por Antonio Bicudo Leme, "há trinta anos pouco mais ou menos", na freguesia desmembrada de Taubaté, "sítio de morada do dito fundador e pelos anos adiante".

São esses fatos equívocos, improcedentes ou, a qualquer título, inaceitáveis? - Não. Muito ao contrário: eles nos informam sobre uma igreja existente na época e aludem a uma capela, anteriormente erigida naquele sítio por Antônio Bicudo Leme, "o fundador".

(3). - Cfre. Enciclopédia Britânica, vol. 21, pág. 601. Londres, 1971.

(4). - João Martins de Almeida, Vultos de Pindamonhangaba, pág. 5, Rio de Janeiro, 1958. 
Ora, a tradição do povoamento do Brasil mostra que os primitivos aglomerados humanos surgiam, quase sem exceção, em torno de uma capela. Comprovam-no os topônimos da maioria das cidades brasilciras, em memória dos santos, oragos das capelas que lhes eram dedicadas.

Esse foi o costume seguido na fundação de Pindamonhangaba: Antônio Bicuro Leme e Brás Esteves Leme, uma vez instalados em terras do feudo da Condessa de Vimieiro, em Taubaté, dispuseram-se a ali erguer uma capela. E, assim o fizeram.

O documento, omitindo, embora, o nome de Brás Esteves Leme, conta que o fabriqueiro da primitiva capela foi Antônio Bicudo Leme. Depois,

"com a acurencia de varios moradores que foram assituando veyo a ser freguezia".

Eis um relato típico da fundação de um povoado com a notícia de quem o fundou. Tudo perfeitamente legal conforme os usos e costumes.

Temos aí, a fundação e o fundador.

Fantasia, invencionice, mistificação? - Nada disso. Verdade em que acreditamos, não só porque o documento merece fé, mas porque ontros comprovantes o corroboram.

Nesta altura, alguem perguntará: - "E ninguem mais, alem de Ataide, teria conhecido o famoso Livro do Tombo e visto o documento"? - Sim, houve outro estudioso que o compulsou e que atesta a existência do documento em questão: foi o historiador Benedito Marcondes Homem de Melo, autor do trabalho Pindamonhangaba, publicado no Almanaque Literário de São Paulo, de 1876, e de um Dicionário da Província de São Paulo.

Essa informação é de boa fonte. Está no livro Algumas notas para a história de Pindamonhangaba, de Waldomiro de Abreu, às páginas 75 e 76.

Em artigo firmado com as iniciais R. de L., pub'icado em $O$ Estaaio de S. Paulo, de 16-3-1901, sob o título "Por cidades e Vilas - Pindamonhangaba", lê-se: "Do respectivo Livro do Tombo consta que em 1647 já existia ali uma igreja regularmente construida". - Anote-se a data da existência da igreja: 1647; e a do artigo: 1901.

Quem teria sido R. de L.? - Waldomiro de Abreu, mais uma vez, nos elucida: - Foi o Sr. Manuel Rodrigues de Leiroz, jorna- 
lista, então residente em São Paulo, identificado mais tarde pelo professor Pedro Silva (5).

Consequentemente, tanto o Livro do Tombo como o documento são reais. Isso é o importante.

Anote-se, de passagem, que o fato do Livro do Tombo ter sido aherto em determinada época não exclui a possibilidade de mencionar ele fatos ocorridos anteriormente como, no caso, a ereção da capela pelos fundadores Antônio Bicudo Leme e Brás Esteves Leme.

Quaisquer discrepâncias entre as datas mencionadas por Ataide numa e noutra edição de seu trabalho não invalidam o principal: A fundação do povoado de Pindamonhangaba por Antônio Bicudo Leme, juntamente com Brás Esteves Leme, segundo consta de outros informes dignos de crédito.

\section{OUTRAS PROVAS.}

Haverá, além do documento em apreço, outras fontes históricas que permitam atribuir a fundação de Pindamonhangaba aos irmãos Leme? - Sim, e valiosas, sem falar na tradição secular, que confirma o fato.

O testemunho de Pedro Taques de Almeida Pais Leme é tido entre os mais válidos pelos estudiosos dos problemas históricos do velho São Paulo. Convem conhecer o que esse eminente historiador escreveu na sua Nobiliarquia Paulistana Histórica e Genealógica, sobre Antônio Bicudo Leme:

"Antonio Bicudo Leme, natural e cidadão de São Paulo, que fez o seu estabelecimento nas vilas de Taubaté e Pindamonhangaba, onde se fez recomendavel pela suas ações e cabedal, que adquiriu da grandeza das Minas-Gerais dos primeiros anos do seu descobrimentos. Foi pessoa de um geral respeito e estimação. Praticou vistudes morais, com amor da justiça e da retidão, nos empregos que teve com os cargos da república. Teve cognome de varão-santo, e foi conhecido. e ainda hoje existe pelo cognome de Via-Sacra. Faleceu na dita vila de Pindamonhangaba com testamento em 6 de junho de 1716, e ordenou no dito testamento que o seu cadaver fosse sepultado aos pés das três cruzes da via-sacra, dentro dos muros da igreja de Nossa Senhora do Bom Successo de Pinda-

(5). - Waldomiro de Abreu, op. cit., nota 4ī, à pág. 80. 
monhangaba, de cuja vila foi Antonio Bicudo Leme, com seu irmão, genros, filhos e parentes, o fundador, porque ao seu requerimento atendeu el-rei $\mathrm{D}$. João $\mathrm{V}$ para permitir a criação desta vila, contra a oposição eficaz e vigorosa que faziam os moradores da vila de Taubaté, que jamais quizeram consentir que aquela povoação se eregisse em vila" (6).

Onde se lê "D. João V", leia-se "D. Catarina", então na regência do governo de Portugal.

Esse equívoco, devido ao fato de $\mathrm{D}$. João $\mathrm{V}$ haver subido ao trono em 1706, precisamente no ano da publicação do decreto da emancipaçấo de Pindamonhangaba, em nada afeta o mérito do texto acima transcrito.

Como se vê, de tal monta foi a influência dos irmãos Leme e de sua gens nos primórdios de Pindamonhangaba, que Pedro Taques lhes atribui a iniciativa da fundação da vila .

Temos aí Antônio Bicudo Leme e Brās Esteves Leme, já reconhecicios como os fundadores da povoação, reconhecidos também como os fundadores da vila nascente, porque - diz Pedro Taques foram eles que provocaram o decreto do governo de Portugal, que homologou o ato revolucionário da emancipação de Pindamonhangaba.

Diante dessa evidência do relevante papel desempenhado pelos irmãos Leme na história da cidade, é de se perguntar: e os outros, os" que teriam passado por lá, antes, que fizeram, onde se ocultam?

A versão de Pedro Taques é confirmada, mutatis mutandis, pelos historiadores Silva Leme, Genealogia Paulistana, vol. VI, págs. 298 e 327; Azevedo Marques, Apontamentos Históricos, Geográficos, Biográficos, Estatísticos e Noticiosos da Província de São Paulo. Tomo II, pág. 169; Eugênio Egas, Os Municipios Paulistas, vol. II, pág. 1.362, Jacinto Ribeiro, Cronologia Paulista, vol. I, pág. 607, e Tomás Oscar Marcondes de Souza, O Estado de São Paulo, pág. 379, sem" esquecer Ataide Marcondes, Pindamonhangaba, 2.a edição, pág. 264, 398, 399 e 77 (parte II) e Rômulo Campos D'Arace, Retrato da Princesa do Norte, págs. 14 e 15.

Dir-se-á que esses historiadores vieram nas pegadas de Pedro Taques. Se, em parte, assim é, isso significa que eles aceitaram e endossaram o juizo do autorizado cronista paulistano:

(6) . - Pedro Taques, op . cit., Tomo III, pág. 173, São Paulo, 1953. 


\section{A INTERPRETAÇÃO DAS FONTES HISTORICAS.}

A velha máxima da legislação romana scire leges non est verba earum tenere sed vim ac potestatem aplica-se cabalmente à exegese dos documentos históricos. De fato, o historiador como o legista não deve ater-se tão só às palavras do texto submetido a exame, mas ao seu espírito e ao seu alcance.

As regras de interpretação das fontes históricas, notadamente dos documentos, encontram-se hoje formuladas no procedimento metodológico denominado heurística, que tem por objeto a descoberta dos fatos, através da pesquica documental.

Os iniciados nessas técnicas concordam, como os jurisperitos romanos em que as palavras não devem ser tomadas ad litteram, mas lato sensu. E, embora não cheguem, como o poeta francề ao extremo de dizer que as palavras nada valem, les mots ne dizent rien, entende que é preciso saber interpretá-las, atendendo às circunstâncias que as ditaram. Em outros termos, a heurística ensina a ler os documentos.

Deixando de lado as minúcias dessa disciplina, pois aqui não cabe dissertar sobre elas, procuremos situar o problema no âmbito mais vasto da metodologia histórica, a fim de verificar como se deve proceder para a comprovação de um fato pretérito. E se algum mestre for chamado a nos dar lições, não tenhamos dúvidas de que ele nos advertirá, in limine:

"A história não é uma ciência de observação, mas de raciocínio" (7).

Vale dizer que não basta ver os fato: na sua nudez, isto é, na sua expressão pura e simples. E' forçoso interpretá-los através do raciocinio, operação do espírito que nos permite estabelecer nossos juizos, à margem de qualquer influência, mesmo das que se apre'entam com a chancela do visum et repertum.

Ao cabo dessa operação, que temos? - Uma verdade científica incontratável ou simplesmente uma conjectura? - Gastão Boissier responde:

"Não é exata a pretenção de que a história chegou a ser uma ciência interamente nova, nem mesmo uma ciência. Aperfeiçou os seus métodos mais não mudou a sua natureza. Aproxima-se mais

(7). - Langlois et Seignobos, Introduction aux Etules Historiques, pág. 276. Paris, 1898 . 
da verdade, mais não encontrou o meio de alcança-la sempre, nem jamais encontrará. E nescessário que se resigne a não ser mais do que uma ciência de conjeturas; os métodos que usa são no fundo os que sempre empregou e eu não creio que haja outros. Acusamos os historiadores antigos de se contentarem com a verossimilhança. Será que os nossos podem abster-se sempre dela?"

"Por conseguinte, devemos resignar-nos, como fazíam os antigos, a construir a verdade através dos moldes da verossimilhança" (9).

Enrico De Michelis, em Il problema delle Scienze Storiche (pág. 16, Turim, 1915) lembra que Renan em Souvenirs d'Enfance et de Jeunesse, compara a ciência histórica a um conjunto de métodos conjecturais que se modificam sem sessar e que serão esquecidos dentro de um século.

Aceito esse critério, o historiador se liberta de muitos preconceitos, entre os quais o primado do documento, como bem o reconhece Fernando Whitaker da Cunha em $O$ Conceito da História:

- "A definição do documento, no entanto, não pode ser compreendida numa época tal como a nossa em que critérios mais agudos são usados. O documento é uma vox mortua, como o dotrinam os heuristas (que tiveram um precursor em Mabillon) mas o que precisamos é de "uma vox viva", como o testemunho que nos dê a vera latitude e a pulsassão do acontecimento transmitido" (10).

Linhas adiante essa pertinente observação de Lucien Febvre:

"A história se faz com documentos escritos, sem dúvida, quando eles existem. Mas, na falta deles a história pode reconstituir-se e deve tenta-lo a qualquer preço".

$\mathrm{E}$, ainda no mesmo ensaio, à página 36 :

"Guilherme Bauer, igualmente em livro célebre, exprime-se pela presença de outras importantes fontes históricas, alem das meramentes documentais sendo que Spengler, alem disso tudo,

(9). - Gaston Boissier, op. cit., pág. 126.

(10). - Fernando Whitaker da Cunha, O Conceito da História, pág. 31, São Paulo, 1958. 
mostra a necessidade do historiador ser dotado de poderosa intuição para capitar o verdadeiro sentido das coisas".

De tudo se conclui que, no caso da fundação de Pindamonhangaba, ainda que inexistisse o documento contestado, sobrariam "outras importantes fontes históricas", para se atribuir aos irmãos Leme o título de fundadores.

Nessa ordem de considerações, merece ser lembrada a advertência de M. Philippi, reitor da Universidade de Giessen, no sentido de que a crítica dos textos não venha a perder-me em minúcias de somenos importância.

"Coteja-se - escreveu ele - pelo prazer de cotejar; restauram-se com preucauções infinitas documentos sem valor; constata-se assim que se dá maior importância aos materiais do estudo do a seu resultados intelectuais" (11).

A obra já citada de Langlois e Seignobos é um breviário de preciosos ensinamentos para todos os estudiosos da história. Ouça-se a lição sempre atual desses eminentes mestres sobre o critério que se deve adotar na avaliação das fontes históricas.

"Toda ciência se constitui pela aproximação de várias observações: Os fatos científicos são pontos sobre os quais concordam as observações diferentes. Cada observação está sujeita a erros que não podem serem inteiramente eliminados; mas se várias informações concordam, não é plausivel que o façam com fundamento no mesmo erro; a razão mais provavel da concordância é que os observadores viram a mesma realidade e descreveram-na todos exatamente. Os erros pessoais tendem a divergir, são as observações exatas que concordam" (12).

Esse texto de Langlois Seignobos aplica-se "como uma luva" ao problema da fundação de Pindamonhangaba. Atente-se no seguinte: E' inconteste que a tradição, o documento do Livro do Tombo e o juizo de ilustres historiadores apontam Antônio Bicudo Leme e Brás Esteves Leme como fundadores do povoado de Pindamonhangaba e construtores da primitiva capela de São José. Sobre estes fatos principais há concordância daquelas diferentes fontes históricas. Pouco importa que se encontrem divergências a respeito de

(11). - Cfre. Langlois e Seignobos, op. cit., pág. 105.

(12). - Langlois e Seignobos, op. cit., pág. 168. 
pormenores de menor importância entre um documento e outro e, até, em pontos assinalados da obra de um mesmo autor. São os erros pessoais que não afetam as observações concordantes. Tais erros, quando existem, são miuçalhas que não impressionam o investigador avisado, mesmo por que, de minimis non curat praetor.

O historiador das origens de Pindamonhangaba, após sereno exame do problema, à luz dos mais rigorosos processos científicos, podem dizer como o juiz ao prolatar a sua sentença:

"Vistos e examinados os autos, os fundadores de Pindamonhangaba são Antônio Bicudo Leme e Brás Esteves Leme".

Eis o veredicto inapelável da história, que há de permanecer pelos séculos adiante, irremovível como a verdade.

APENDICE.

Crônica publicada no jornal "Tribuna do Norte", de Pindamonhangaba, em 28 de março de 1915, sobre as origens da Capela de São José.

ORIGEM DA CAPEILA DO PATRIACHA S. JOSE.

A missa que no dia 19 do corrente foi celebrada na capella de S. José, sita na Praça B. do Rio Branco, fez-nos lembrar da origem desta capella, que poucos haverão que possam conhecel-a.

Foi instituida no $1^{\circ}$ quartel do século XVII, pelos fidalgos da primeira nobreza de S. Paulo: Braz Esteves Leme, alcaide-mor, seu irmão Antônio Bicudo Leme, seu filho Manoel da Costa Leme e seus dois genros José Corrêa de Magalhães e Pedro da Fonseca de Magalhães.

Como se sabe, terminada a agitação em que permaneceu por tanto tempo a Peninsula Iberica, invadida pelos arabes, e depois de espulsos e vencidos estes, foram os fidalgos portuguezes dispensados dos serviços que vinham prestando a sua patria, defendendo-a dos invasores, que pretendiam conquistal-a .

Resultou dahi ficarem privados os valentes batalhadores dos recursos necessarios para manterem-se, sendo possuidores unicamente de castellos com ricos brasões, mas que nada produziam. Isto os levou a procurarem nas terras que então haviam sido descobertas, outros meios de vida, que os livrassem da pobreza para onde iam todos rapidamente caminhando. 
Foram deste numero os fidalgos que mais tarde mandaram construir a capella do Patriarcha S. José.

Vindo de Portugal, onde deixaram seu solar com brazão attestando sua nobreza, foram estabelecer-se em Parnahyba, de onde mais tarde transferiram sua residencia para Taubaté, que já era a segunda villa da Capitania de S. Paulo.

Homens todos afeitos a vida das armas, rude e trabalhosa, não podiam encontrar difficuldade em irem por sua vez ao centro dos sertões descobrir oiro que constava existir por lá em abundancia.

E assim deliberando fizeram voto, ao partir para essa conquista de, sendo felizes em sua empreza, mandar, em seu regresso, construir uma capella sob a invocação do Patriarcha S. José.

E como tivessem alcançado o que desejavam, logo que voltaram trataram de dar cumprimento a promessa, mandando edificar a capella que tinham promettido, e que foi construida no lugar em que hoje existe esta cidade, e em propriedade pertencente aos instituidores.

Edificada a capella, que devia ficar sujeita a um administrador, e possuir patrimonio com rendas que dessem para satisfazer os encargos religiosos, como festas annuaes, missas e outros creados pelos seus instituidores, era natural que junto a Igreja fossem logo se construindo habitações particulares, com consentimento do administrador, bem entendido.

O que é certo é que no fim de poucos annos, estava alli formada uma povoação, que para ser equiparada a qualquer villa só dependia de uma Matriz. Não podia a Igreja existente prestar-se a esse fim, por estar sujeita, como dissemos, a uma administração particular e não poder ficar subordinada á outrem, nem mesmo ao Parocho. Finalmente ficou assentada a construcção de uma outra Igreja sob a invocação de N. S. do Bom Successo, esposa de S. José, que serviria de Matriz.

Isto explica a rasão de não ter sido $\mathbf{S}$. José, cuja capella já existia alli, o Padroeiro de nossa cidade.

Um dos ultimos administradores da capella foi o coronel de milicia Manoel da Cunha Portes de El-Rei, residente em Taubaté. Por sua morte passou a ser administrada por seu filho Miguel de Godoy Moreira, a quem succedeu o alferes José de Godoy Moreira, o filho mais velho de Miguel de Godoy, sob cuja administração extinguiu-se o vinculo, passando então os bens que o constituiam a pertencer, na fórma da lei, a seu herdeiro.

Achando-se já bastante arruinada a Igreja primitiva, quando o alferes José de Godoy tomou a administração da capella, promptamente cuidou este de construir uma nova Igreja, que é exactamente a que existe na Praça B. do 
Rio Branco e na qual por muitos annos celebraram-se pomposas festas, todas promovidas pela familia Godoy, que na mesma mantinha um capellão, obrigado a celebrar todos os domingos e dias santos.

Afinal com o tempo e com o desapparecimento da familia protectora da capella, acabaram-se as festas; mas a Igreja ahi está attestando os serviços que seus fundadores prestaram á nossa santa religiảo; e felizmente em perfeito estado de conservação, graças unicamente ao religioso zelo de alguns poucos representantes dos ultimos administradores da capella, que podem olhar com certo orgulho para essa herança que seus maiores thes deixaram e merece bem ser conservada. 